\title{
Scene-based and object-centered inhibition of return: Evidence for dual orienting mechanisms
}

\author{
STEVEN P. TIPPER, HEATHER JORDAN, and BRUCE WEAVER \\ University of Wales, Bangor, Gwynedd, Wales
}

\begin{abstract}
We investigated whether inhibition of return (IOR) could be observed in location-based, scene-based, and object-centered frames of reference. IOR was found to move both with a separate cued object (scene-based) and with a location within a single rotating object (object-centered). Importantly, however, IOR was also associated with the environmental location cued when cuing was of a separate object (scene-based), whereas facilitation of the cued location was found when cuing was of a component within an object. These results suggest that location is of central importance to scene-based representations of separate objects, which appear to be encoded in viewer-centered coordinates, whereas environmental locus is of little relevance when attention orients within a single object. The results also provide further evidence for the coexistence of both excitation and inhibition associated with uninformative exogenous cues.
\end{abstract}

When an organism searches a visual environment for a particular object, it is essential that, after attention has been oriented to a location, it is not reoriented there shortly afterwards. For efficient search, it is necessary that attention move to novel unexamined loci. The perseveration of attention to the same locus would seriously impair search performance. One means by which search could be made efficient is for an automatic inhibition mechanism to prevent attention returning to an examined stimulus.

Posner and Cohen (1984) were the first to demonstrate that such an inhibition mechanism may exist. Their procedure was elegant in its simplicity. Three boxes were presented on the horizontal axis of a cathode ray tube. One of the peripheral boxes was cued by brightening its contours. It was assumed that this peripheral cue would automatically summon attention. The central box was then cued, drawing attention away from the initially cued peripheral box. Subjects were instructed to fixate on the center of the display throughout the trial and respond as quickly as possible to a target (small bright box) presented in the center of one of the peripheral boxes. Two important cuing effects were observed. First, if a target was presented at the cued location within $150 \mathrm{msec}$ of the cue, detection of the target was facilitated relative to the uncued location. The interpretation of this result was that attention was automatically oriented to the sudden peripheral change and was still present at the cued location when the target appeared, hence facilitating detection. However, if the cue-target interval was longer than $300 \mathrm{msec}$, detection of the target in the cued box was impaired. Posner and colleagues called

This research was supported by Grant S06761 from the Biotechnology and Biological Sciences Research Council awarded to S.P.T. Correspondence should be addressed to S. P. Tipper, School of Psychology, University of Wales, Bangor, Gwynedd LL57 2DG, Wales (e-mail: pss060@bangor.ac.uk). this latter effect inhibition of return (IOR; Posner, Rafal, Choate, \& Vaughan, 1985). As the name implies, they suggested that the inhibition prevented the return of attention to the cued location.

IOR is a robust phenomenon, which has been observed in a wide variety of situations. It has been seen, for example, when either keypresseses or saccades are the dependent measure (e.g., Abrams \& Dobkin, 1994), when a target has to be detected (e.g., Maylor, 1985; Posner \& Cohen, 1984), or when either color (e.g., Law, Pratt, \& Abrams, 1995) or shape discrimination is required (Lupiáñez, Milán, Tornay, Madrid, \& Tudela, 1997; Pratt, 1995). One of the more recent issues concerning IOR has been its frame of reference. A number of theorists have proposed that attention does not simply gain access to a spatial map where a spotlight moves from one locus to another, facilitating processing in the illuminated location. Rather, it has been proposed that because one of the main functions of selective attention systems is to link action with particular perceptual inputs, the medium of attention can be object-based, since our actions are directed toward objects (Baylis \& Driver, 1993; Duncan, 1984; Kahneman \& Treisman, 1984).

Tipper, Driver, and Weaver (1991) suggested that IOR may also be object-based. That is, attention engages with objects during search, so it is necessary that attention does not return to a recently examined object. Therefore, they predicted that, if, after cuing, the cued object moved to a new location, inhibition would move with the object. This is precisely what they discovered, supporting the notion that IOR can be object-based. Subsequent work has confirmed that IOR can be object-based (Abrams \& Dobkin, 1994; Gibson \& Egeth, 1994; Jordan \& Tipper, 1998; Tipper, Weaver, Jerreat, \& Burak, 1994; see Tipper \& Weaver, 1998, for review). Although other studies (e.g., Müller $\&$ von Mühlenen, 1996) have questioned the generality of the effect, recent work by Weaver, Lupiáñez, and Wat- 
son (1998) has again confirmed that object-based IOR is a robust effect, although, like other IOR effects, it can decline with practice.

It is also well established now that, in fact, IOR can exist in at least two frames of reference simultaneously. Tipper et al. (1994) and Weaver et al. (1998) have shown both location-based and object-based IOR in the same task. For example, in the Weaver et al. study, three colored boxes were presented equally spaced around fixation (see Figure 1, left panel). After cuing, these boxes rotated through $120^{\circ}$, and then a target was presented briefly in one of them. Replicating previous work, target detection was slower in the box that had been cued, even though it had moved $120^{\circ}$ from the cued locus. However, detection of targets within the box that had moved into the cued location on the computer screen was also impaired, relative to the third condition in which the target appeared in an uncued box in an uncued location (see also Abrams \& Dobkin, 1994, and Gibson \& Egeth, 1994).

The present study further investigated the frames of reference in which IOR can occur. As noted previously by Tipper and Weaver (1998), the distinction between scene-based and object-centered frames is important. Scene-based describes the spatial relationships between separate objects in a scene (e.g., Baylis \& Driver, 1993;

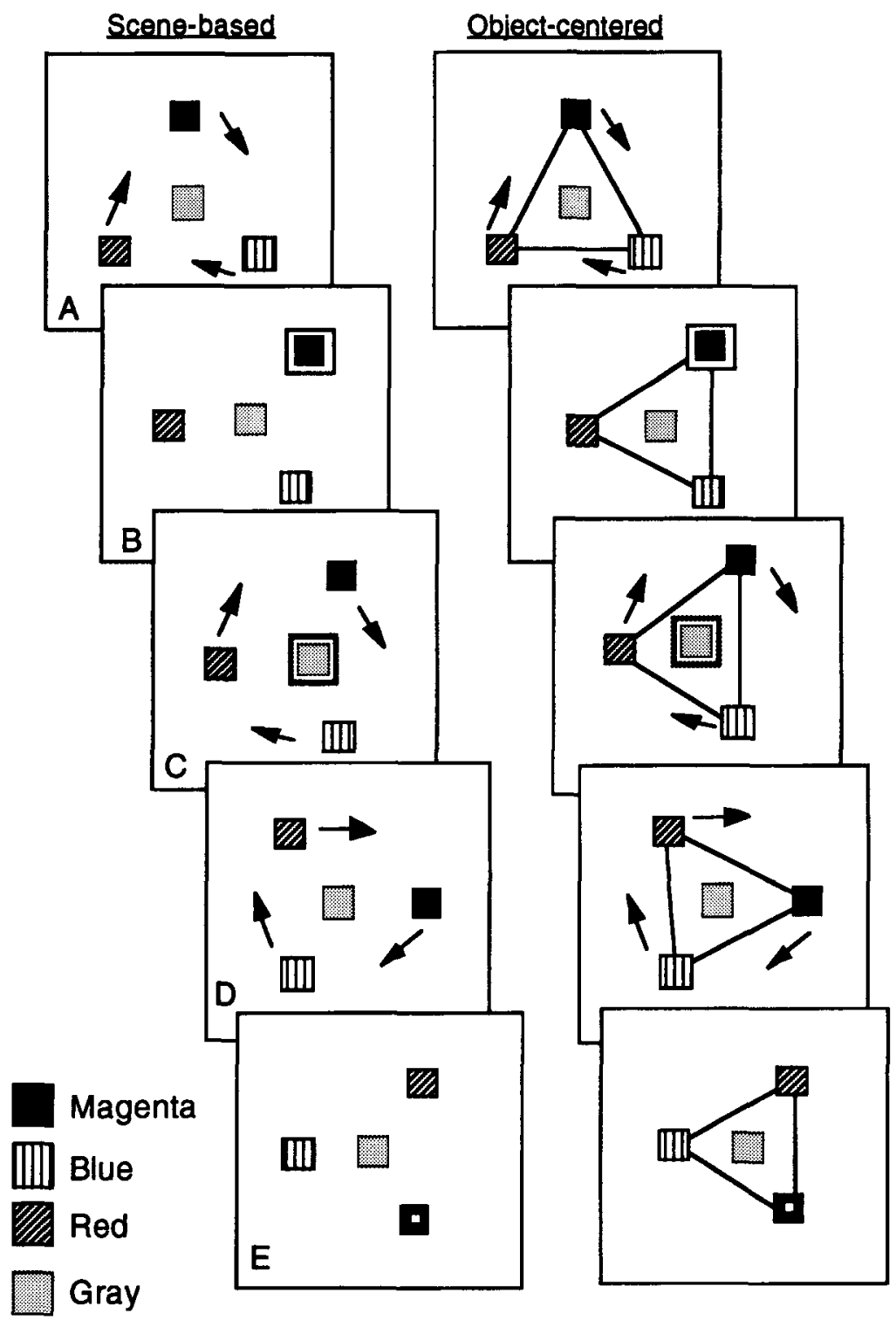

Figure 1. Illustration of the trial sequence used in Experiment 1. The left-hand panel depicts the displays observed in the scene-based reference frame condition, and the right-hand panel depicts those in the object-centered condition. The target appears in the cued object in both panels. See text for details. 
Kahneman, Treisman, \& Gibbs, 1992). This betweenobject relationship is completely flexible, in that two objects could be adjacent or many miles apart. The location of one object is independent of the other. In sharp contrast, object-centered frames are much more similar to location-based frames. In this case, the features of an object are represented within a spatial structural description - that is, a representation of the object that includes an explicit specification of locations within the object (e.g., Biederman, 1987; Marr, 1982; Pinker, 1985). For example, the triangle examined in Experiment 1 (see Figure 1 , right panel) contained locations that were fixed and invariant relative to the other loci in the object. Even though the triangle was an object that could move through space, each corner was constrained relative to the other corners.

Contrasts between scene-based and object-centered frames have been recently observed in studies of neglect. For example, Humphreys and Riddoch $(1994,1995)$ have described a patient who produces neglect in both scenebased and object-centered coordinates, depending on the task. When naming a word (whole-object processing), he neglected the left. However, when treating each letter as a separate object while naming letters, he neglected the right (see also Costello \& Warrington, 1987, Cubelli, Nichelli, Bonito, de Tanti, \& Inzaghi, 1991, and Riddoch, Humphreys, Luckhurst, Burroughs, \& Bateman, 1995).

Of most pertinence to the studies to be reported here, Tipper and Behrmann (1996) also investigated scenebased and object-centered neglect. In previous studies (Behrmann \& Tipper, 1994), subjects had been presented with a barbell stimulus (red circle on the right connected to a blue circle on the left with a black bar). When the barbell remained static, detection of targets on the left of this stimulus was impaired, as expected with these righthemisphere lesions. However, when the barbell slowly rotated around the computer screen through $180^{\circ}$ while subjects viewed it, neglect appeared to move with the object. That is, the left neglect rotated into the good field, such that target detection was now worse on the right side of space in the left side of the object. However, when the black connecting bar was removed, so that two separate circles (scene-based) were observed to rotate, neglect did not rotate with the left circle. This suggested that neglect in this task was mediated by an object-centered frame of reference. Only when attention was directed to one coherent object did neglect rotate.

The same experimental logic was employed in the present experiments. In one condition, we replicated the previous observations of Weaver et al. (1998; see also Tipper \& Weaver, 1998). Three separate and differently colored boxes were presented rotating around the screen. We expected to observe both location-based and objectbased IOR after cuing. Such an outcome would suggest that IOR is mediated by a scene-based representation, since the inhibition is associated with separate objects. However, further work is necessary, because it is possi- ble that the three boxes could be encoded as components of the same object as they rotate around the screen. This is because they maintain a constant invariant relationship with one another-that is, the same between-object distances are maintained as they rotate through the same path at the same speed. These invariant relationships are cues that the three boxes may belong to the same larger object.

Therefore, using the logic employed by Tipper and Behrmann (1996), we compared this separate object condition with a situation in which all the boxes were explicitly connected with black bars to produce a triangle. Although the connected condition versus disconnected condition appears to be a very simple manipulation, these conditions produced dramatically different results between connected and disconnected circles in the Tipper and Behrmann study, and subjects commented that the connected and separate displays do appear quite different as the objects rotate.

As discussed above, we know that IOR can be associated with both the cued object and the location on the computer screen that was cued. We do not know whether, in these particular procedures, inhibition will be associated with one part of a single object when the boxes are connected and whether inhibition will also be associated with the cued location. Previous work by Gibson and Egeth (1994), using quite a different paradigm, has suggested that IOR can be associated with a location within an object, as well as the environmental location cued. In their study, a two-dimensional drawing of an outline brick shape was cued at various corners. After rotating in depth, a target was presented in a location on the brick. The target location could be the same location on the brick as the cue, the same location on the screen as the cue, or a location that had no relationship with the cue. Their results suggested that inhibition moves with the cued corner of the brick. However, it is clearly necessary to extend this issue to confirm this pattern within other procedures that more closely compare scene-based (between-object) and object-centered (within-object) frames.

\section{EXPERIMENT 1}

Experiment 1 was designed to replicate object-based and location-based IOR using the three-box procedure of Weaver et al. (1998) and to compare displays with three separate objects with those in which the three objects were linked to form a triangle.

\section{Method}

Subjects. Twenty undergraduate psychology students ( 5 men, 15 women) from the University of Wales, Bangor (UWB), participated in the study for course credit. They ranged in age from 18 to 33 (mean age $=22.0$ years). All reported normal or corrected-to-normal acuity and showed normal color vision when tested using Dvorine Pseudo-Isochromatic color plates. All subjects were naive to the purpose of the experiment.

Apparatus. Stimulus presentation and reaction time (RT) recording was carried out by an IBM-compatible 486/33 micro- 
computer attached to a color video graphics array (VGA) monitor. The stimuli were presented in VGA medium-resolution mode, at a $70-\mathrm{Hz}$ refresh rate. Responses were collected via digital microswitches on a response box that was interfaced with the computer through the parallel printer port (see Dalrymple-Alford, 1992). RTs were computed to the nearest millisecond using Bovens and Brysbaert's (1990) TIMEX function.

Procedure. Each trial began with a centrally presented prompt to press the start key on the response box when the subject was ready to continue. Once the start key was pressed, the screen cleared. In all trials, a dark gray box was presented in the center of a light gray display. It was surrounded by three colored boxes (blue, red, and magenta) in an imaginary circle around the central box (Figure 1A). In the object-centered (boxes connected into a triangle) condition ( $50 \%$ of the trials), in addition to the four boxes, a line ( 1 pixel in width) was drawn from the center of each peripheral box to the center of the adjacent peripheral box, forming a triangle (Figure 1A, right panel). The peripheral boxes were overlaid on the lines, obscuring them. At a viewing distance of $70 \mathrm{~cm}$ (from a chinrest), the radius of the imaginary circle was $4.4^{\circ}$ of visual angle. The boxes themselves subtended $0.74^{\circ} \times 0.82^{\circ}$ (horizontal $\times$ vertical).

The starting position of each of the three peripheral boxes was variable and randomly determined, with the constraint that each of the peripheral boxes was $120^{\circ}$ (in polar coordinates) from the other two. The boxes appeared in this initial position for $1,000 \mathrm{msec}$ and then began to rotate (either clockwise or counterclockwise) around the central box. The lines were updated appropriately in the objectcentered condition. The apparent motion was achieved by switching of the graphics frames to produce the appearance of smooth motion of the peripheral boxes. The peripheral boxes moved by $7.5^{\circ}$ (in polar coordinates) between each frame and remained visible for $28.6 \mathrm{msec}$. Thus, 48 frames would be required to produce a full $360^{\circ}$ rotation.

After three frames of movement, the motion ceased, and, one frame later $(28.6 \mathrm{msec})$, a peripheral box was replaced by a cue, as shown in Figure 1B. The cue consisted of an enlarged colored box $\left(1.14^{\circ}\right.$ horizontal $\times 1.31^{\circ}$ vertical $)$ with a superimposed white box $\left(0.98^{\circ}\right.$ horizontal $\times 1.15^{\circ}$ vertical $)$ with another colored box $\left(0.41^{\circ}\right.$ horizontal $\times 0.50^{\circ}$ vertical) in the middle. Thus, it appeared as a white hollow box, outlined with a colored line, with a colored center. The peripheral cue was presented for $86 \mathrm{msec}$ and then overwritten by the original peripheral box. One hundred and seventytwo milliseconds after the onset of the peripheral cue, the fixation marker (central box) was cued for $86 \mathrm{msec}$, in exactly the same way as the peripheral cue (as described above; Figure 1C). Simultaneously with the onset of the central cue, the apparent motion of the peripheral boxes resumed (Figure 1D). All subjects were instructed to maintain fixation on the central box throughout each trial. (Pilot studies with this type of stimulus display suggest that subjects do comply with this instruction. Attempts to track a single peripheral object render the task extremely difficult since the target appears in each of the objects with equal probability [ $20 \%$ for each location], the visual angle between the objects is large, and the temporal duration of the targets is brief. The subjects are aware that the easiest strategy is to maintain fixation at the center of the display.)

The apparent motion of the peripheral boxes continued until they had rotated $120^{\circ}$ along the path of the imaginary circle (Figure 1E). The apparent motion then stopped, and, on $60 \%$ of the trials, the target was presented in one of the peripheral boxes for $57 \mathrm{msec}$ (Figure $1 \mathrm{E})$. The SOA between the peripheral cue and target was $598 \mathrm{msec}$. The target consisted of a small white filled box $\left(0.98^{\circ}\right.$ horizontal $\times 1.15^{\circ}$ vertical) that was overlaid on one of the peripheral boxes. The subjects were instructed to press the response key as quickly as possible when the target appeared and to withhold a response on the catch trials. The subjects had $1,000 \mathrm{msec}$ in which to respond on target-present trials. A computer-produced tone provided feedback on error trials. Short rest breaks $(30 \mathrm{sec})$ occurred every 50 trials.

Design. The experiment had a two-factor repeated measures design. The first factor, reference frame, had two levels: scene-based and object-centered. In the scene-based condition, the peripheral boxes were not linked. This was an identical replication of Tipper and Weaver (1998) and Weaver et al. (1998). In the object-centered condition, lines connected the three peripheral boxes. The second factor, cuing, had three levels: In the uncued condition, the target appeared in an uncued box that occupied an uncued location after $120^{\circ}$ of rotation. In the cued-location condition, the target appeared in the uncued object that moved into the cued location. In the cuedobject condition, the target appeared in the cued object that had rotated $120^{\circ}$ into an uncued location.

The subjects completed 40 practice trials ( 4 trials of each targetpresent condition plus 16 catch trials) and 300 experimental trials. In 120 experimental trials, half of which were in the scene-based display, no target appeared (catch trials). The remaining 180 targetpresent trials were made up of 60 trials for each of the three cuing conditions in the scene-based (separate objects) and the objectcentered (triangle) displays in equal proportions.

\section{Results}

RT data. Mean median RTs (for correct trials) and percentage error rates are shown in Figure 2A. The RT data were analyzed with a two-factor repeated measures analysis of variance (ANOVA). The two independent variables were reference frame (with two levels: scene-based [peripheral boxes separate] and object-centered [peripheral boxes joined forming a triangle]) and cuing (with three levels: uncued, cued location, and cued object). There was a reliable main effect for cuing $\left[F(2,38)=4.2, M S_{\mathrm{e}}=\right.$ $1,595.0, p<.05]$, indicating that RTs to peripheral boxes were affected by the cuing condition. Figure $2 \mathrm{~A}$ indicates that, with the exception of cued location in the objectcentered condition, RTs were slower when the location/ object was previously cued. Slower RTs in the cuedlocation and cued-object conditions are indicative of the IOR effect. The main effect for reference frame was not significant $\left[F(1,19)=0.6, M S_{\mathrm{e}}=158.7\right.$, n.s.].

The interaction between reference frame and cuing was significant $\left[F(2,38)=4.8, M S_{\mathrm{e}}=971.3, p<.05\right]$. To further analyze this interaction, two ANOVAs were undertaken to examine separately the effects for location (uncued vs. cued location) and object (uncued vs. cued object) cuing conditions. For the first analysis (uncued and cued location), a significant interaction between reference frame (scene-based vs. object-centered) and cuing was obtained $\left[F(1,19)=7.0, M S_{\mathrm{e}}=1,911.0, p<.05\right]$. In sharp contrast, only a main effect of cuing was observed in the second analysis [uncued and cued object, $F(1,19)=$ $\left.5.3, M S_{\mathrm{e}}=1,814.5, p<.05\right]$; there was no hint of an interaction between scene-based/object-centered frames and cuing $\left[F(1,19)=0.2, M S_{\mathrm{e}}=59.5\right.$, n.s. $]$.

Thus, the scene-based (separate objects) condition replicated the finding of object-based IOR as observed by Tipper and Weaver (1998) using a similar procedure and subsequent work carried out using the same procedure 

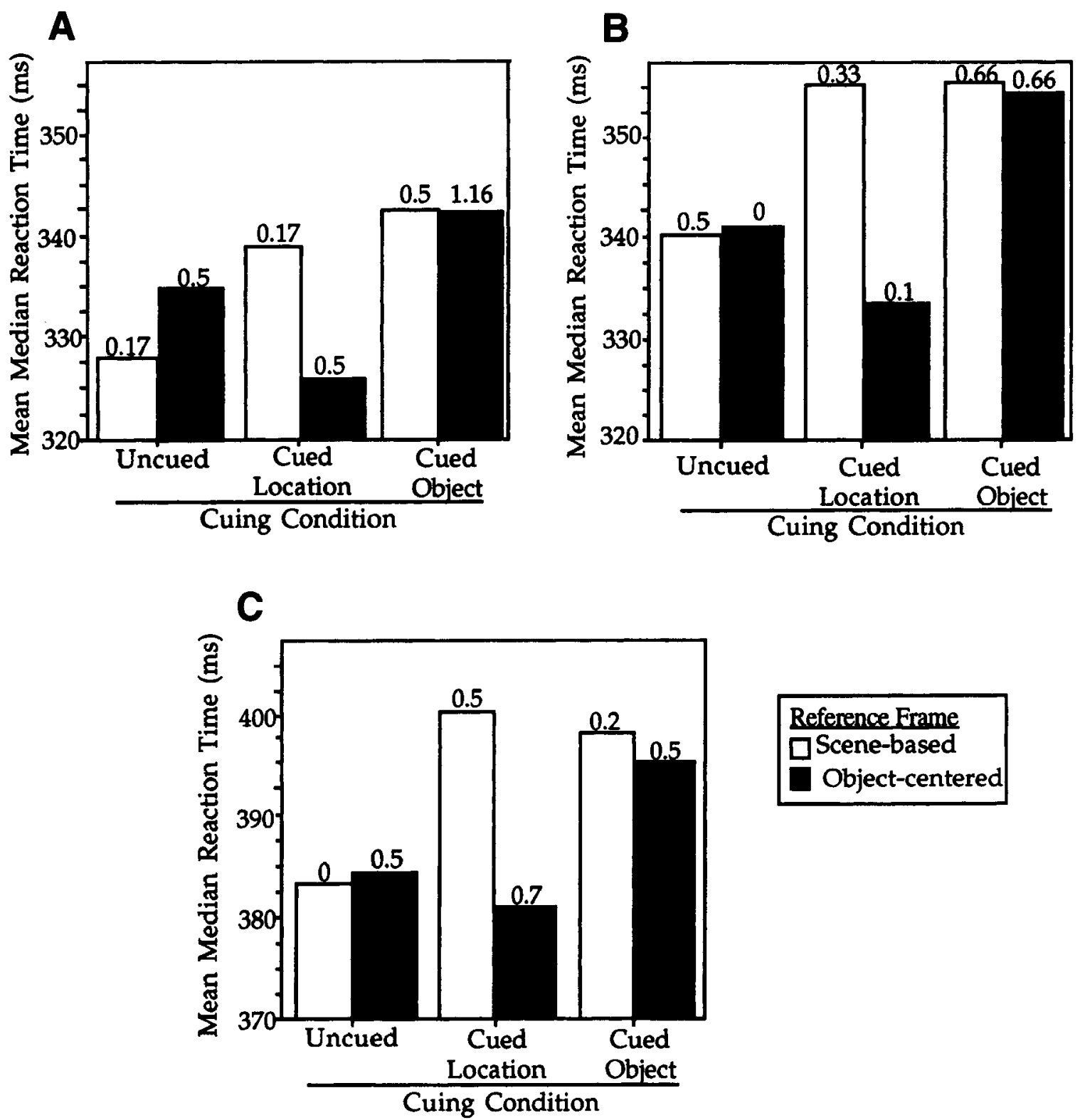

Figure 2. Mean median reaction times of correct trials and percentage error rates for trials in Experiment 1 (panel A), Experiment 2 (panel B), and Experiment 3 (panel C).

(e.g., Weaver et al., 1998). The pattern of data is quite different when the peripheral boxes are joined to form a triangle. Although RTs to a target in the cued-object condition were slower than in the uncued condition, a trend toward a facilitatory effect was observed for the cued location.

Error data. The mean error percentages for all three cuing conditions (excluding the catch trials) for both displays are shown in Figure 2A. The error rates were very low, indicating that the subjects completed the task with very little difficulty. A nonparametric Friedman ANOVA was performed on the error rates to ensure that the accuracy rate did not differ between conditions. An analysis of the six conditions that were contained in the $2 \times 3$ (reference frame $\times$ cuing) design of the experiment revealed no significant differences $\left[\chi^{2}(5, n=20)=1.42\right.$, n.s.]. The error percentages for the catch trials for the scene-based (separate objects) and object-centered (triangle) conditions were 2.2 and 1.5, respectively. Analysis of these error percentages also revealed no reliable differences $\left[\chi^{2}(1, n=20)=0.2\right.$, n.s. $]$.

\section{Discussion}

The analysis of the object-based (uncued and cued object) IOR shows that IOR is obtained both when a separate object in scene-based coordinates is cued and when a part of a single object in object-centered coordinates is cued. These results therefore replicate previous work ex- 
amining scene-based (separate object) IOR (Abrams \& Dobkin, 1994; Ro \& Rafal, in press; Tipper et al., 1991; Tipper, Howard, \& Meegan, in press; Tipper et al., 1994; Weaver et al., 1998), and it also replicates Gibson and Egeth's (1994) findings for within-object IOR. However, what is much more surprising is the location-based (uncued and cued location) IOR. In scene-based (separate objects) coordinates the effect is again replicated, showing that IOR can be associated with location. In sharp contrast, a small facilitation effect is observed when a location is cued in the (within-object) object-centered reference frame.

This latter dramatic contrast between location-based cuing in scene-based and object-centered conditions requires replication for three reasons. First, we did not predict this result, and it could have important implications for models of IOR. Second, it contrasts with Gibson and Egeth's (1994) observation of significant location-based IOR. Third, in a previous pilot study, we observed location and object-centered IOR in a similar triangle condition (see Tipper \& Weaver, 1998). Importantly, however, this previous study was a between-subjects design, in which subjects only saw the triangle display. As Poulton (1982) so cogently argued, within- and between-subjects designs are qualitatively different. The influential companion effects he describes may have determined the results here. For example, when the subjects experienced both scene-based (separate object) and object-centered (triangle) conditions randomly within the same experiment, the structural properties of the triangle might have been more salient due to the contrast when observing the three color boxes rotating separately. Therefore, in Experiment 2 , we attempted to replicate and extend the observations of Experiment 1.

\section{EXPERIMENT 2}

In Experiment 1, the triangle might have produced a subjective surface within the lines that joined the peripheral boxes. To test whether this was an important feature of the display, the object-centered display used in Experiment 2 consisted of lines running from each peripheral box to the center box. This "spoke" display is shown in Figure 3.

\section{Method}

Subjects. Twenty-one undergraduate psychology students ( 3 men, 18 women) from UWB volunteered to participate for course credit. They ranged in age from 16 to 26 years (mean age $=21.9$ years). All reported normal or corrected-to-normal vision and had normal color vision when tested with Dvorine Pseudo-Isochromatic plates. The subjects were naive to the purpose of the experiment.

One subject, whose median RTs in the scene-based cued-object condition were more than 2.5 SD slower than those in the other target-present conditions, was excluded from the study. There is no obvious explanation for this observation, and it was unlike the pattern of data for all the remaining subjects.

Apparatus and Procedure. The same apparatus and procedure were used as in Experiment 1. However, the manner in which the peripheral boxes were linked in the triangle condition was changed. A typical trial sequence is illustrated in Figure 3. Rather than lines join- ing the peripheral boxes to each other, lines radiated from the central box to each of the individual boxes. Thus, they appeared as spokes on a wheel. The procedure was identical to that of Experiment 1.

\section{Results and Discussion}

The median RTs (Figure 2B) were analyzed as before using a 2 (reference frame: scene-based and objectcentered) $\times 3$ (cuing: uncued, cued location, and cued object) repeated measures ANOVA. There was a main effect for cuing $\left[F(2,38)=6.3, M S_{\mathrm{e}}=1,924.4, p<.01\right]$. Again, this is indicative of IOR. Consistent with Experiment 1 , there was no main effect of reference frame $\left[F(1,19)=3.8, M S_{\mathrm{e}}=15,678.4\right.$, n.s. $]$.

The interaction between reference frame (scene-based vs. object-centered) and cuing was significant $[F(2,38)=$ $\left.5.4, M S_{\mathrm{e}}=1,499.8, p<.01\right]$. Separate $2 \times 2$ (reference frame $\times$ cuing) ANOVAs for object- and location-based IOR were carried out as before to examine the pattern of data for cuing objects and locations. As before, there was a significant main effect for cuing in the object condition $\left[F(1,19)=11.5, M S_{\mathrm{e}}=3,577.8, p<.01\right]$, but no interaction between reference frame and cuing $[F(1,19)=0.2$, $M S_{\mathrm{e}}=66.6, \mathrm{n} . \mathrm{s}$.]. This indicates slower RTs to cued objects in both the scene-based condition and the objectcentered condition. The main effect for cuing locations was not significant $\left[F(1,19)=1.6, M S_{\mathrm{e}}=245.0\right.$, n.s. $]$. However, the interaction between cuing and reference frame was highly significant $\left[F(1,19)=16.9, M S_{\mathrm{e}}=16.9\right.$, $p<.001]$. Again, this reflects an inhibitory effect in the scene-based condition and a contrasting facilitatory effect in the object-centered condition.

The mean error percentages for all conditions (excluding catch trials) are reported in Figure 2B. Again, the error rates were so low that we used a nonparametric Friedman ANOVA to analyze the data for differences between the six conditions. There was no reliable difference between the conditions $\left[\chi^{2}(5, n=20)=1.48\right.$, n.s.]. The percentage errors for the scene-based and object-centered catch trials were $0.93 \%$ each.

Experiment 2 clearly replicated Experiment 1 . Inhibition appears to move both with a separate object (scene-based) and with a location within an object (object-centered). Of most importance, we have also replicated the dramatic contrast in location-based IOR: In scene-based coordinates, the usual inhibition effect was observed; however, in object-centered frames, a small facilitation effect was produced.

\section{EXPERIMENT 3}

There is a possibly crucial difference between the displays presented in the scene-based and object-centered conditions in Experiments 1 and 2. In the scene-based condition, the display consisted of three peripheral boxes and a central box. The display in the object-centered condition was produced by the addition of lines that link the boxes. Therefore, the complexity of the two displays was not balanced, and this confound should be controlled for. In Experiment 3, we attempted to replicate Experi- 


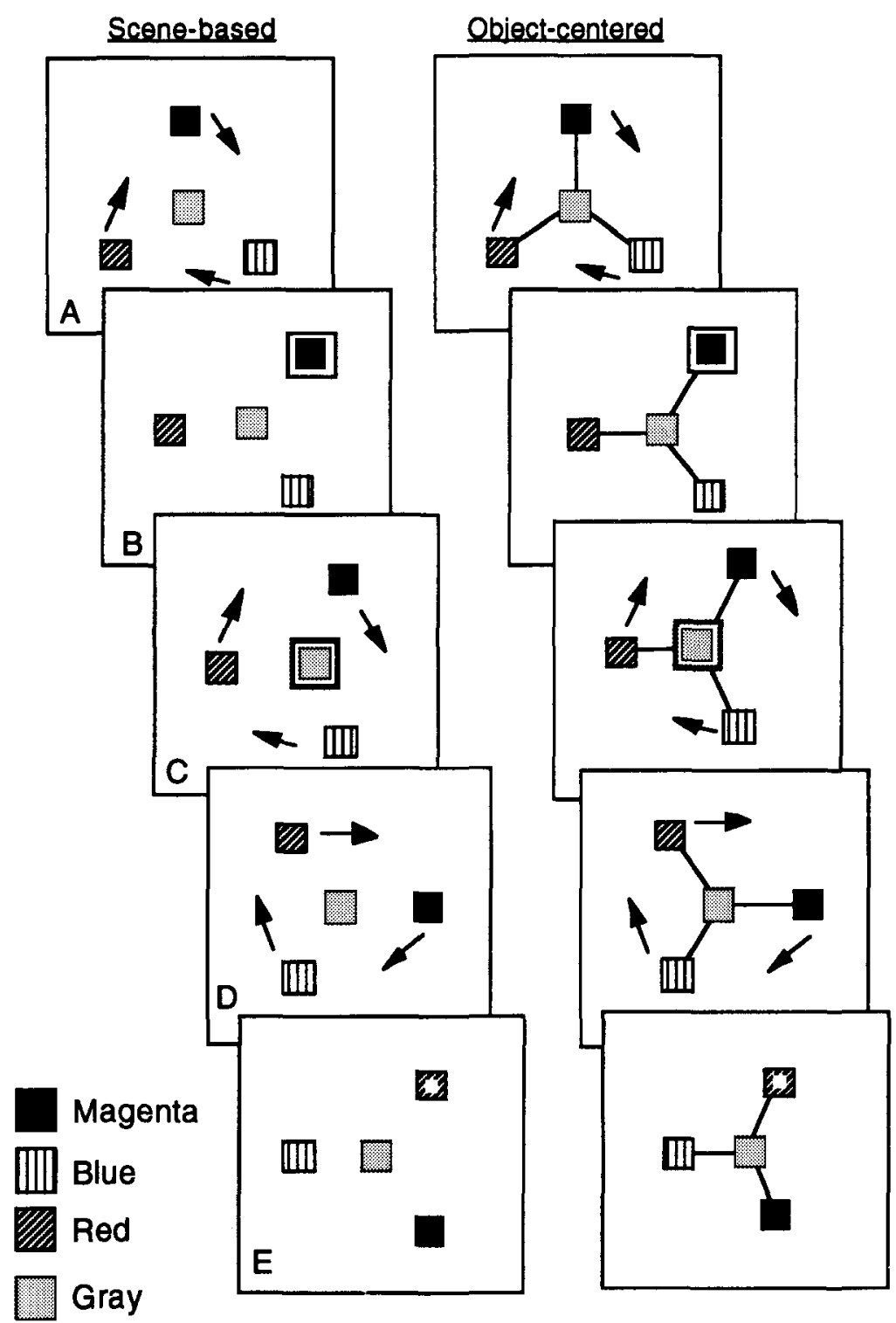

Figure 3. Illustration of the trial sequence used in Experiment 2. The left-hand panel depicts the displays observed in the scene-based reference frame conditions, and the right-hand panel depicts those in the object-centered condition. The target appears in the cued location in both panels. See text for details.

ment 1 while ensuring that the complexity (amount) of visual information falling on the retina is identical. Thus, the black lines in the object-centered (triangle) display used in Experiment 1 were added to the scene-based display, but in a manner in which no single object was created.

\section{Method}

Subjects. Sixteen undergraduate psychology students $(5$ men, 11 women) from UWB volunteered to participate for course credit. They ranged in age from 18 to 35 years (mean age $=25.4$ years). All reported normal or corrected-to-normal vision and had normal color vision when tested with Dvorine Pseudo-Isochromatic plates. The subjects were naive to the purpose of the experiment.

Apparatus and Procedure. The same apparatus and procedure were used as in Experiment 1. However, in the scene-based (objects separate) reference frame condition, lines were added so that the complexity of display in both conditions was identical. This was achieved by splitting the connecting lines and presenting them at a position and orientation that was rotated $180^{\circ}$ in relation to each peripheral box. Thus, identical lines were presented in both conditions; however, in the object condition, they pointed inward and connected to form a triangle, and, in the scene-based condition, they pointed outward. A typical trial sequence is illustrated in Figure 4. The procedure was identical to that of Experiment 1.

\section{Results}

Trials with incorrect, slow (>1,000 msec), and anticipatory $(<100 \mathrm{msec})$ responses were excluded from the analysis as before. Two subjects were excluded from the analysis because their mean error rate in all conditions 


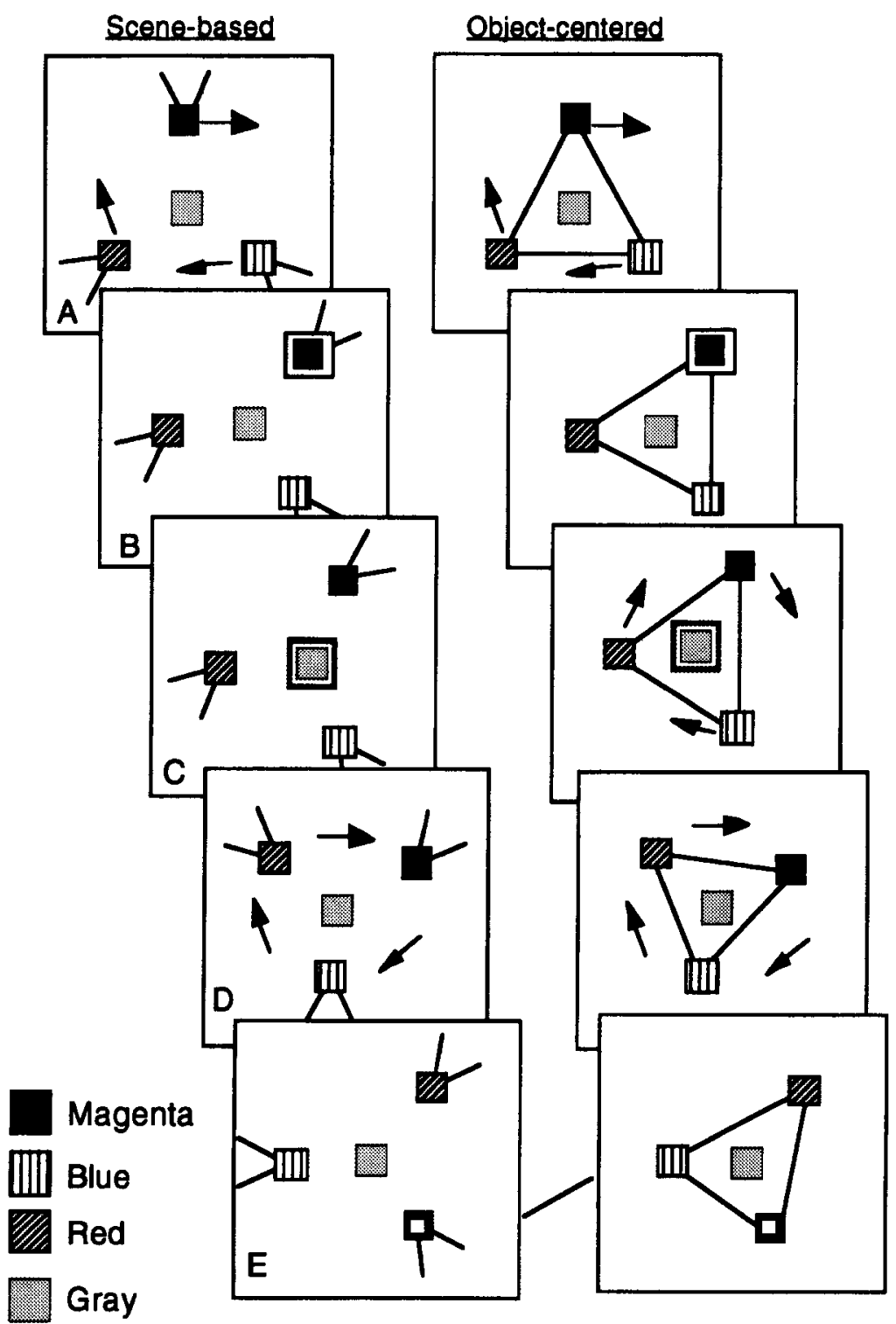

Figure 4. Illustration of the trial sequence used in Experiment 3. The left-hand panel depicts the displays observed in the scene-based reference frame condition, and the right-hand panel depicts those in the object-centered condition. The target appears in the cued object in both panels. See text for details.

was more than $8 \%$, which is far higher than the typical error rates in this series of experiments $(M=0.5 \%, S D=$ $1.3 \%$ ). (Their high error rate was evenly distributed across conditions.)

A 2 (reference frame: scene-based [separate] and objectcentered [triangle]) $\times 3$ (cuing: uncued, cued location, and cued object) repeated measures ANOVA was carried out on the remaining median RTs for each condition. There was no main effect for either cuing $\left[F(2,26)=2.2, M S_{\mathrm{e}}=\right.$ $1,145.4$, n.s. $]$ or reference frame $\left[F(1,13)=2.2, M S_{\mathrm{e}}=\right.$ 913.4, n.s.].

Consistent with Experiments 1 and 2, there was a significant interaction between reference frame and cuing
$\left[F(2,26)=4.9, M S_{\mathrm{e}}=769.5, p<.05\right]$. Separate 2 (reference frame) $\times 2$ (cuing) repeated measures ANOVAs were conducted to examine this interaction as before. Experiments 1 and 2 showed a significant main effect for cuing in the object frame, and the same pattern of data was found here, although only approaching significance $\left[F(1,13)=3.7, M S_{\mathrm{e}}=2,225.2, p<.08\right]$. Detection of targets appearing in a cued object tended to be slower in both the scene-based condition and the object-centered condition. There was no main effect for reference frame $\left[F(1,13)=0.012, M S_{\mathrm{e}}=5.2\right.$, n.s. $]$ and no interaction between reference frame and cuing $\left[F(1,13)=0.2, M S_{\mathrm{e}}=\right.$ $33.0, \mathrm{n} . \mathrm{s}$.]. As before, in the location frame, there was no 
main effect for either reference frame $[F(1,13)=4.3$, $\left.M S_{\mathrm{e}}=1,089.4, \mathrm{n} . \mathrm{s}.\right]$ or cuing $\left[F(1,13)=1.5, M S_{\mathrm{e}}=936.4\right.$, n.s.]. However, the important interaction between reference frame and cuing was significant $[F(1,13)=9.3$, $\left.M S_{\mathrm{e}}=1,330.9, p<.01\right]$. Experiment 3 therefore replicated Experiments 1 and 2 in inhibition of location in the scene-based condition and a contrasting facilitatory effect in the object-centered condition.

The mean error percentages for all conditions (excluding catch trials) are reported in Figure 2C. As before, a nonparametric Freidman ANOVA was used to analyze the data for differences between the conditions. There were no reliable differences in the percentage errors between conditions $\left[\chi^{2}(5, n=14)=5.65\right.$, n.s. $]$. The mean error rates for the catch trials in the scene-based and object-centered conditions were $0.4 \%$ and $1.3 \%$, respectively. An analysis of the error rate percentages indicated that this difference was not significant $\left[\chi^{2}(1, n=14)\right.$ $=1.14$, n.s.].

\section{Combined Data}

Experiments 1-3 show the same pattern of data. In order to increase the power of the analysis, the data from these experiments were combined and analyzed using a 3 (experiment: Experiment 1, Experiment 2, and Experiment 3) $\times 2$ (reference frame: scene-based and objectcentered) $\times 3$ (cuing: uncued, cued location, and cued object) mixed-design ANOVA. The variable of experiment was between subjects, and reference frame and cuing were repeated measures.

There was a main effect for experiment $[F(2,51)=$ $\left.4.4, M S_{\mathrm{e}}=81,659.7, p<.05\right]$, but there were no significant interactions involving experiment. The main effect for experiment reflects a between-subjects difference in median RTs, but this makes no difference to the pattern of effects, reflected in the lack of any interactions between experiment and other variables. There was a main effect for scene-based versus object-centered frames $[F(1,51)=$ $\left.6.5, M S_{\mathrm{e}}=2,371.5, p<.05\right]$, since the subjects were slower to detect the target when the three boxes were not connected (scene-based). There was also a main effect for cuing $\left[F(2,51)=10.9, M S_{\mathrm{e}}=4,243.1, p<.0001\right]$. The interaction between reference frame and cuing was highly reliable $\left[F(2,102)=14.0, M S_{\mathrm{e}}=2,375.7, p<.0001\right]$. Planned means comparisons indicated both significant location-based IOR $[t(51)=-5.1, p<.0001]$ and significant object-based IOR $[t(51)=-5.2, p<.0001]$ in the scene-based (separate object) condition. There was also significant object-based IOR in the object-centered condition $[t(51)=-3.5, p<.001]$ and a contrasting significant facilitatory location-based effect $[t(51)=2.1, p<.05]$.

\section{Discussion}

Experiment 3 therefore replicated the pattern of results observed in Experiments 1 and 2. Thus, even when stimulus display complexity is held constant, there is a qualitative difference between scene-based and objectcentered representations when cuing a location. In the former case, the cue produces inhibition; in the latter case, the cue produces a trend toward facilitation. In contrast, when a moving object or part of a moving object is cued, inhibition is observed in both scene-based and objectcentered representations. The combined analysis of all three experiments detected no hint of an interaction between experiments, thus confirming that all three experiments did indeed produce the same pattern of results.

\section{GENERAL DISCUSSION}

We have been concerned with contrasting scene-based and object-centered frames. It is clear that the visual system treats perceptual inputs in fundamentally different ways depending on whether they are coded as single or multiple objects. One of the main features that define objects as "separate" is that they occupy separate locations in space. When the visual system needs to "keep track" of separate moving objects in the scene, it must code the location of each object individually. Separate objects have locations encoded within a coordinate frame intrinsic to the viewer: That is, object location could be coded relative to retinal, head-centered, or hand-centered frames, depending on the task (see Humphreys \& Riddoch, 1994; Tipper, Lortie, \& Baylis, 1992; Tipper et al., 1994). However, "keeping track" of objects that form part of a larger single object does not require individual location coding. The visual processing system may track the location of the global object and recover the location of object elements relative to a frame of reference based on the object: That is, it is object-centered.

These experiments have shown that IOR moves both with a separate cued object (scene-based) and with a component element within one object (object-centered). However, by far the most surprising result is the observation that location-based IOR varies qualitatively depending on the objects' frame of reference. Thus, in scenebased frames, the locus cued remains inhibited, whereas, in object-centered frames, the cued locus is associated with excitation, and subsequent processing appears to be facilitated. Location-based IOR was not observed in this series of experiments when an elemental location of a large single object (object-centered condition) was cued.

There is now an increasing body of evidence showing that location-based cuing effects are qualitatively different from object-based effects. For example, Tipper and Weaver (1998) reported that, in the scene-based threebox task described here, location-based IOR persists over substantially longer stimulus onset asynchronies than does object-based IOR. Second, Tipper and Weaver also noted that the location-based effect can be associated with an empty featureless location. That is, after the cuing of an object, the cued location remains empty until a new object moves into it. This is clear evidence that the effect is not associated with object-based frames. In contrast, Tipper et al. (1994) showed that object-based IOR occurs only when the object is visible at the time of cuing. If it is occluded by a different object, no inhibition is as- 
sociated with the object. Third, Abrams and Dobkin (1994) have shown that location-based IOR can be observed when a target is to be detected, as well as when an eye movement, signaled via a central arrow, has to be made to the cued location. In contrast, object-based IOR is observed only in the perceptual measure of target detection. Further work has suggested that the location- and objectbased frames may be mediated by different neural systems. Location-based IOR is mediated by the superior colliculus, whereas object-based IOR appears to be cortical (see Tipper et al., 1997, for further discussion). Therefore, our findings here contribute to this growing list of dissociations between location- and object-based IOR effects.

Our main concern, however, is to provide an account of the contrasting location-based cuing effects in the scene-based and object-centered conditions. As discussed above, object-centered and scene-based representations are mediated by different frames of reference, and the two types of information are used by the perceptual-motor systems quite differently. Scene-based frames are based on the viewer. That is, the locations of objects are encoded in various possible viewer-based frames, such as head-centered (Anderson \& Zipser, 1990) or handcentered (Tipper et al., in press). In such scene-based frames, the location of objects is fundamental to behavior. Thus, when searching for a particular object, there must be a representation of the location occupied by the object. When searching for a mislaid pencil in one's office, for example, it is crucial that attention does not return to environmental loci recently examined. In contrast, when searching within an object-centered frame, the environmental locus of object features is of little importance. For example, when orienting attention within an object to find a critical component (e.g., does the lead pencil have a point?), where that component is, relative to the wider environment, is irrelevant.

As a quite different example, showing the importance of location to scene-based frames, consider the task of reaching to and grasping an object. There are two components to this task (see Jeannerod, 1988). The first is to move the hand to the location of the target rather than to a possible distractor. Therefore, in the reach component, location of an object in the wider environment is absolutely fundamental: The hand is directed to a particular environmental location. The second stage is the grasp component. This requires qualitatively different forms of information, which are based on the intrinsic (objectcentered) properties of the object and which are independent of the environmental location occupied by the object. Thus, to grasp the pencil, whether it is on the desk or coffee table is irrelevant after the hand has been moved to that environmental location.

Therefore, we suggest that environmental location is critical for scene-based frames but is essentially irrelevant for object-centered frames. A remaining puzzle is why the location-based cuing effect in object-centered frames is facilitatory. Posner and Cohen (1984) originally suggested that uninformative exogenous cues were simultaneously associated with excitation and inhibition:

We have now identified two effects that occur when a peripheral cue is presented [i.e., facilitation and inhibition]. We believe that these two effects overlap in time and that the efficiency of detection results from their joint influence. (p. 548)

Recent work has begun to find further evidence for this idea (Gibson \& Egeth, 1994; Tassinari, Aglioti, Chelazzi, Peru, \& Berlucchi, 1994; but see Tipper et al., in press). For example, Tipper et al. (1997) examined objectbased IOR in two split-brain subjects. The hypothesis was that if object-based IOR was mediated by cortical systems requiring direct corpus callosum connections, the inhibition would only be observed as long as the object moved within a visual field. If the object crossed the visual midline, and hence to the other hemisphere, no IOR would be associated with the cued object. Indeed, objectbased IOR was observed when the object remained in the same visual field. However, surprisingly, and counter to any of their original predictions, significant object-based facilitation was observed when the cued object crossed the midline. These results were taken as evidence for the coexistence of both object-based excitation and objectbased inhibition. Object-based inhibition presumably requires cortical and direct corpus callosum systems, whereas the facilitation seems to be reliant on other, as yet unidentified, systems that enable transfer between hemispheres.

Therefore, in the present experiments, we suggest that, after cuing, all frames are associated with excitation. Subsequent to this, inhibition is also associated with the cued square, and this inhibition moves with this separate object or component of a single object. In the scene-based frame, because the location cued is critical for search and action, this is also associated with inhibition. However, as discussed above, environmental location of the cue when it is within a single object is not relevant. Hence, no inhibition is associated with the location, and, thus, the initial excitation is revealed. Clearly, these surprising findings require confirmation and extension to new procedures because they have important implications for our understanding of IOR and how the various frames of reference interact during perceptual-motor processing.

\section{REFERENCES}

Abrams, R. A., \& DobKIN, R. S. (1994). Inhibition of return: Effects of attentional cuing on eye movement latencies. Journal of Experimental Psychology: Human Perception \& Performance, 20, 467-477.

ANDERSON, R. A., \& ZIPSER, D. (1990). A network model for learned spatial representation in the posterior parietal cortex. In J. L. McGaugh, N. M. Weinberger, \& G. Lynch (Eds.), Brain organization and memory: Cells, systems, and circuits (pp. 382-407). New York: Oxford University Press. 
BAyLIS, G. C., \& DRIVER, J. (1993). Visual attention and objects: Evidence for hierarchical coding of location. Journal of Experimental Psychology: Human Perception \& Performance, 19, 451-470.

BEHRMANN, M., \& TIPPER, S. P. (1994). Object-based attentional mechanisms: Evidence from patients with unilateral neglect. In C. Umiltà \& M. Moscovitch (Eds.), Attention and performance XV: Conscious and nonconscious information processing (pp. 351-375). Cambridge, MA: MIT Press.

BIEDERMAN, I. (1987). Recognition by components: A theory of human image understanding. Psychological Review, 94, 115-145.

Bovens, N., \& BRYSBAERT, M. (1990). IBM PC/XT/AT and PS/2 Turbo Pascal timing with extended resolution. Behavior Research Methods, Instruments, \& Computers, 22, 332-334.

Costello, A. DE L., \& WARrington, E. K. (1987). The dissociation of visuospatial neglect and visual dyslexia. Journal of Neurology, Neurosurgery \& Psychiatry, 50, $1110-1116$.

Cubelli, R., Nichelli, P., Bonito, V., De Tanti, A., \& Inzaghi, M. G. (1991). Different patterns of dissociation in unilateral neglect. Brain \& Cognition, 15, 139-159

DALRYMPLE-ALFORD, E. C. (1992). Response-key input via the IBM PC/XT/AT's parallel printer port. Behavior Research Methods, Instruments, \& Computers, 24, 78-79.

DUNCAN, J. (1984). Selective attention and the organization of visual information. Journal of Experimental Psychology: General, 113, 501-517.

GIBSON, B. S., \& EGETH, H. (1994). Inhibition of return to object-based and environment-based locations. Perception \& Psychophysics, 55, 323-339.

Humphreys, G. W., \& Riddoch, M. J. (1994). Attention to withinobject and between-object spatial representations: Multiple sites for visual selection. Cognitive Neuropsychology, 11, 207-241.

HuMPHREYS, G. W., \& RiDDOCH, M. J. (1995). Separate coding of space within and between perceptual objects: Evidence from unilateral visual neglect. Cognitive Neuropsychology, 12, 283-311.

JEANNEROD, M. (1988). The neural and behavioural organization of goal-directed movements. Oxford: Oxford University Press, Clarendon Press.

JORDAN, H., \& TIPPER, S. P. (1998). Object-based inhibition of return in static displays. Psychonomic Bulletin \& Review, 5, 504-509.

Kahneman, D., \& Treisman, A. M. (1984). Changing views of attention and automaticity. In R. Parasuraman \& D. Davies (Eds.), Varieties of attention (pp. 29-61). Orlando, FL: Academic Press.

Kahneman, D., Treisman, A. [M.], \& GibBs, B. J. (1992). The reviewing of object files: Object-specific integration of information. Cognitive Psychology, 24, 175-219.

Law, M. B., Pratt, J., \& Abrams, R. A. (1995). Color-based inhibition of return. Perception \& Psychophysics, 57, 402-408.

Lupiáñez, J., Milán, E. G., Tornay, F. J., Madrid, E., \& Tudela, P. (1997). Does IOR occur in discrimination tasks? Yes, it does, but later. Perception \& Psychophysics, 59, 1241-1254.

MARR, D. (1982). Vision. San Francisco: W. H. Freeman.

MAYLOR, E. A. (1985). Facilitatory and inhibitory components of orienting in visual space. In M. I. Posner \& O. S. M. Marin (Eds.), Attention and performance $X I$ (pp. 189-207). Hillsdale, NJ; Erlbaum.

MüLLER, H. J., \& VON MüHLENEN, A. (1996). Attentional tracking and inhibition of return in dynamic displays. Perception \& Psychophysics, 58, 224-249.
Pinker, S. (1985). Visual cognition: An introduction. In S. Pinker (Ed.), Visual cognition (pp. 9-15). Cambridge: MA: MIT Press.

Posner, M. I., \& Cohen, Y. A. (1984). Components of visual orienting. In H. Bouma \& D. G. Bouwhuis (Eds.), Attention and Performance $X$ (pp. 531-556). Hillsdale, NJ: Erlbaum.

Posner, M. I., Rafal, R., Choate, L. S., \& Vaughan, J. (1985). Inhibition of return: Neural basis and function. Cognitive Neuropsychology, 2, 211-228.

Poulton, E. C. (1982). Influential companions: Effects of one strategy on another in the within subjects designs of cognitive psychology. Psychological Bulletin, 91, 673-693.

PratT, J. (1995). Inhibition of return in a discrimination task. Psychonomic Bulletin \& Review, 2, 117-120.

Riddoch, M. J., Humphreys, G. W., LuCKhurst, L., Burroughs, E., \& Bateman, A. (1995). "Paradoxical neglect": Spatial representations, hemisphere-specific activation, and spatial cueing. Cognitive Neuropsychology, 12, 569-604.

Ro, T., \& RAFAL, R. (in press). Apparent motion and attention: An object-based facilitatory component of visual orienting. Perception \& Psychophysics.

Tassinari, G., Aglioti, S., Chelazzi, L., Peru, A., \& Berlucchi, G. (1994). Do peripheral non-informative cues induce early facilitation of target detection? Vision Research, 34, 179-189.

TrPPER, S. P., \& BehrmanN, M. (1996). Object-centred not scene-based visual neglect. Journal of Experimental Psychology: Human Perception \& Performance, 22, 1261-1278.

TipPer, S. P., Driver, J., \& Weaver, B. (1991). Object-centred inhibition of return of visual attention. Quarterly Journal of Experimental Psychology: Human Experimental Psychology, 43A, 289-298.

TTPPER, S. P., HowARD, L. A., \& MEEGAN, D. (in press). Mechanisms of selective attention gain access to hand-centred frames of reference: Evidence from interference and negative priming effects. In $S$. R. Jackson (Ed.), Vision and action: Advances in cognition series. London: University College Press.

Tipper, S. P., Lortie, C., \& Baylis, G. C. (1992). Selective reaching: Evidence for action-centered attention. Journal of Experimental Psychology: Human Perception \& Performance, 18, 891-905.

TiPPER, S. P., RaFal, R., Reuter-LoRenz, P. A., StarkVeldT, Y., Ro, T., EGLY, R., DANZINGER, S., \& WEAVER, B. (1997). Object-based facilitation and inhibition from visual orienting in the human split-brain. Journal of Experimental Psychology: Human Perception \& Performance, 23, 1522-1532.

TIPPER, S. P., \& WEAVER, B. (1998). The medium of attention: Locationbased, object-centred, or scene-based? In R. Wright (Ed.), Visual attention (pp. 77-107). New York: Oxford University Press.

Tipper, S. P., Weaver, B., Jerreat, L. M., \& Burak, A. L. (1994). Object-based and environment-based inhibition of return of visual attention. Journal of Experimental Psychology: Human Perception \& Performance, 20, 478-499.

Weaver, B., LuPiáñEz, J., \& Watson, F. L. (1998). The effects of practice on object-based, location-based, and static-display inhibition of return. Perception \& Psychophysics, 60, 993-1003.

(Manuscript received June 12, 1997; revision accepted for publication December 27, 1997.) 